\title{
Treatment of hypertension: mono-therapy versus [Zofenopril and Hydrochlorothiazide] combined therapy: A review
}

\author{
Francesco Crespi* \\ Department of Biology, Neurosciences CEDD GlaxoSmithKline, Medicines Research Centre, Italy
}

\begin{abstract}
The need of at least two antihypertensive drugs to achieve optimal blood pressure (BP) control in patients with hypertension appears more and more evident. In particular, the combination of the angiotensin-converting enzyme inhibitor zofenopril together with hydrochlorothiazide (diuretic) at the dose $30 / 12.5 \mathrm{mg} / \mathrm{day}$ respectively is now approved in Italy, France, Switzerland and Greece for the treatment of mild to moderate hypertension.

The aim of this work is therefore to collect results from all available reports in order to analyse efficacy, safety and metabolic effects of such combined therapy versus Zofenopril alone. Efficacy and safety data were threfore assessed taking into account the number of subjects (weighted analysis).

It emerges that in various clinical trials the combined therapy was significantly more effective in treating hypertension when comparing to mono-therapy with the further advantage of a safety profile. Therefore the combined therapy analysed here appears to be a positive improvement of the currently available therapy for patients with BP.
\end{abstract}

\section{Introduction}

Angiotensin-converting enzyme inhibitors (ACEIs) interfere with the renin-angiotensin system and have beneficial actions when used in a range of cardiovascular disorders. Over the years, following preclinical evidences, several second- and third-generation ACEIs have been introduced into the clinic. In particular, preclinical and clinical findings have established Zofenopril ( $\mathrm{Z}$ ) as a potent sulphydryl ACE inhibitor, characterized by high lipophilicity, high potency, significant tissue selectivity, antioxidant and tissue protective activities and a long duration of action.

Efficacy as well as tolerability is major quality of an antihypertensive drug while the adverse effects associated with treatment are among the most common causes of poor compliance with antihypertensive treatment $[1,2]$. Therefore, antihypertensive drugs combined with a better tolerability profile can aid compliance and help better the hypertensive population to benefit from experiences in dedicated clinical studies [3]. Indeed, one of the major purposes of Research is not only developing drugs with new mechanisms of action, but also improving already existing drugs with either more effectiveness and/ or fewer adverse effects.

For instance, the combination of an ACE inhibitor and a diuretic presents three distinct advantages:

- Reduced probability of adverse metabolic effects often associated with the use of high-dose diuretic therapy only;

- Reduced tendency of thiazide diuretics to lower serum potassium levels;

- Z has a direct antioxidant effect in humans [4] and therefore may counteract the putative increase of oxidant activity via an activation of the rennin-angiotensin system due to the diuretic hydrochlorothiazide (HCTZ) [5,6].

\section{Further advantages are}

I. The fixed combination $\mathrm{Z}+\mathrm{HCTZ}$ diminish the amount of tablets per day, thus improving patient compliance.

II. Combination therapy may be superior or, at least, as equally effective as mono-therapy in the prevention of organ damage associated with hypertension. In particular, it has been shown that ACE inhibitor therapy in combination with a diuretic can reduce left ventricular hypertrophy (LVH) [5] and can help in retarding the progression of renal failure in diabetic and other types of nephropathy [7-9].

The objective of this paper is therefore to further assess the comparative efficacy and tolerability of $Z$ alone versus $Z$ in combination with HCTZ. The feasibility of evaluation of glucose, urine protein and lipid profile during treatment is also considered when available.

\section{Methods}

Efficacy and tolerability data have been obtained from the studies included in this meta-analysis that were identified through

Correspondence to: Francesco Crespi, Department of Biology, Neurosciences CEDD GlaxoSmithKline, Medicines Research Centre, Italy, Tel: +39 3481452720; E-mail: fm.crespi@libero.it

Key words: Angiotensin-Converting Enzyme Inhibitors (ACEIs), zofenopril, hydrochlorothiazide, mild-to-moderate hypertension, mono-therapy, combined therapy

Received: May 12, 2017; Accepted: June 03, 2017; Published: June 05, 2017 
bibliographic searches in computerised databases [i.e. PubMed] using the terms ' $\mathrm{Z}$ ' and 'clinical trial' as well as from unpublished reports. In particular, two double blind parallel studies have presented data from patients treated with only $\mathrm{Z}(\mathrm{n}=18$ or $\mathrm{n}=19$, respectively) or only HCTZ $(\mathrm{n}=19 \mathrm{each})$ at doses $30 \mathrm{mg} /$ day $\mathrm{n}=12$ or $60 \mathrm{mg} /$ day $\mathrm{n}=6$ [10] or doses $25 \mathrm{mg} /$ day $\mathrm{n}=10$ or $50 \mathrm{mg} /$ day $\mathrm{n}=9$ [11], respectively.

Malacco and Omboni also in a double blind parallel study, displayed data from 89 patients treated with only $Z$ ( $30 \mathrm{mg} /$ day) or 167 with Z + HCTZ (30 + $12.5 \mathrm{mg} /$ day) [12].

Parati, et al. again in a double blind parallel study displayed data from 106 patients treated with various doses of $Z$ ( 15 , or 30 , or $60 \mathrm{mg} /$ day, $\mathrm{n}=36,36$, or 34 , respectively) or 71 patients with two doses of HCTZ $(12.5$, or $25 \mathrm{mg} /$ day, $\mathrm{n}=36$, or 35 , respectively) or 172 patients treated with Z+HCTZ (Z: dose: $15 \mathrm{mg} /$ day: $\mathrm{n}=70 ; 30 \mathrm{mg} /$ day: $\mathrm{n}=69 ; 60$ mg/day: $\mathrm{n}=33$; HCTZ dose:12.5 mg/day: $\mathrm{n}=101 ; 25 \mathrm{mg} /$ day: $\mathrm{n}=71$ ) [13].

Mäkel $[14,15]$ are two open PMSs (unpublished) to evaluate the efficacy, tolerability and safety of $\mathrm{Z}$ during treatment of hypertension [14] or during treatment of hypertension in diabetic patients [15]. In both pMSs data are from patients treated with only $\mathrm{Z}$ or with $\mathrm{Z}+\mathrm{HCTZ}$ at various doses as follow:

- 1042 patients treated with $\mathrm{Z}$ alone: $7.5 \mathrm{mg} /$ day: $\mathrm{n}=11 ; 15 \mathrm{mg} /$ day: $\mathrm{n}=331 ; 30 \mathrm{mg} /$ day: $\mathrm{n}=666 ; 45 \mathrm{mg} /$ day: $\mathrm{n}=9 ; 60 \mathrm{mg} /$ day: $\mathrm{n}=25$;

- 261 patients treated with Z + HCTZ [i.e. Z: $7.5 \mathrm{mg} /$ day: $\mathrm{n}=3 ; 15 \mathrm{mg} /$ day: $\mathrm{n}=64 ; 30 \mathrm{mg} /$ day: $\mathrm{n}=181 ; 60 \mathrm{mg} /$ day: $\mathrm{n}=13+$ constant dosage of HCTZ i.e. $12.5 \mathrm{mg} /$ day: $\mathrm{n}=261$ ] [14].

- 446 patients treated with $\mathrm{Z}$ alone: $7.5 \mathrm{mg}$ /day: $\mathrm{n}=1 ; 15 \mathrm{mg} /$ day: $\mathrm{n}=191 ; 30 \mathrm{mg} /$ day: $\mathrm{n}=240 ; 45 \mathrm{mg} /$ day: $\mathrm{n}=2 ; 60 \mathrm{mg} /$ day: $\mathrm{n}=12$.

- 108 patients treated with Z+HCTZ [i.e. Z: $7.5 \mathrm{mg} /$ day: $\mathrm{n}=1$; $15 \mathrm{mg} /$ day: $\mathrm{n}=42 ; 30 \mathrm{mg} /$ day: $\mathrm{n}=61 ; 60 \mathrm{mg} /$ day: $\mathrm{n}=4+$ constant dosage of HCTZ i.e. $12.5 \mathrm{mg} /$ day: $\mathrm{n}=108$ ] [15].

Malacco, et al. described a multicenter (58 centers), randomized, double blind parallel-group study. Briefly, a 4-week placebo washout period, during which previous antihypertensive treatment had to be withdrawn, was followed by 12 weeks of randomized treatment with $\mathrm{Z}+\mathrm{HCTZ}(30+12.5 \mathrm{mg}$ /day $)$ or monotherapy with $\mathrm{Z}$ alone $30 \mathrm{mg}$, respectively. Patients were randomized in a ratio of 2:1:1. Randomization was done by blocks and generated by a computer. The final per protocol population for this post hoc analysis comprised 246 patients ( $\mathrm{n}=157 \mathrm{Z}+$ HCTZ and $\mathrm{n}=89 \mathrm{Z}$ mono-therapy) [16].

\section{Results}

The results are taking into account only the real number of subjects effectively taking part in each study. For instance, since the patients in references [10] and [11] seem to be the same subject's data have been therefore included in the analysis once. All data were normalized to $\mathrm{mmol} / \mathrm{L} \pm$ Standard Deviation.

The data from subjects treated with $\mathrm{Z}$ alone, HCTZ alone or $\mathrm{Z}+$ HCTZ have been analysed as distinct groups (Table 1).

Statistical comparison of systolic and diastolic blood pressure: Only the above six studies [i.e., ref \# 10-16] include comparisons between $\mathrm{Z}$ alone and the combined therapy $\mathrm{Z}+\mathrm{HCTZ}$ and are then used for statistics [Student $t$ test].

In all these studies, the antihypertensive effect of $Z$ alone as well as that of combined therapy $\mathrm{Z}+\mathrm{HCTZ}$ is statistically significant $[\mathrm{p}<$
0.05] versus pre-treatment values of both systolic and diastolic blood pressure [SBP and DBP, respectively]. Furthermore, the contribution of HCTZ to the anti-hypertensive effect of $Z$ is statistically significant [p $<0.05$ ] for both SBP and DBP with exception for SBP in reference [14] (Figure 1).

Response rates and Mantel-Heanszel odd ratios: Response was defined as having a reduction of $10 \mathrm{mmHg}$ or more of the diastolic blood pressure or having a diastolic blood pressure not higher than 90 $\mathrm{mmHg}$.

Response rates or individual data were available only in three studies [13-15] and could be therefore analysed. In each one of these studies as well as and on the whole the odd ratio is significantly greater than 1.00 , thus HCTZ is significantly strengthening the antihypertensive effect of $\mathrm{Z}$ alone (Table 2 and Figure 2).

In the post hoc analysis described in study [16] 246 patients [139 men, 107 women; aged $54 \pm 11$ S.D. years] were treated, and precisely $\mathrm{n}=89$ with $\mathrm{Z}$ monotherapy or $\mathrm{n}=157$ with the combined therapy $\mathrm{Z}+$ HCTZ. These two groups were selected with very similar characteristics of age as well as clinical features as shown in figures 3 and 4 . Indeed, no significant between-group differences were found before treatments.

Initial clinical traits (mean \pm S.D.) of the two groups of patients that will be successively treated with either $\mathrm{Z}+\mathrm{HCTZ}$ or with $\mathrm{Z}$ alone. At the end of the 12 weeks of double-blind daily treatment with $Z$ $+\operatorname{HCTZ}(30 \mathrm{mg}+12.5 \mathrm{mg})$ or with $\mathrm{Z}$ alone $(30 \mathrm{mg})$ the reduction

Table 1. The data from subjects treated with $Z$ alone, HCTZ alone or $Z+$ HCTZ have been analysed as distinct groups. [*In 25 cases in the studies [14] and [15] the gender was not recorded].

\begin{tabular}{|c|c|c|c|c|}
\hline Ref. \# & n= & Age & S.D. & Gender \\
\hline 10 & 38 & 54.5 & 9.5 & $16 / 22$ \\
\hline 12 & 256 & 52 & 12.3 & $150 / 106$ \\
\hline 13 & 349 & 56.6 & 11.8 & $198 / 151$ \\
\hline 14 & 1303 & 61.7 & 12.7 & $609 / 673$ \\
\hline 15 & 554 & 64.7 & 12.1 & $281 / 269$ \\
\hline 16 & 246 & 54 & 11 & $139 / 107$ \\
\hline Total & $\mathbf{2 7 4 6}$ & $\mathbf{5 5 . 9}$ & $\mathbf{1 1 . 4}$ & $\mathbf{1 3 9 3 / 1 3 2 8}^{*}$ \\
\hline
\end{tabular}
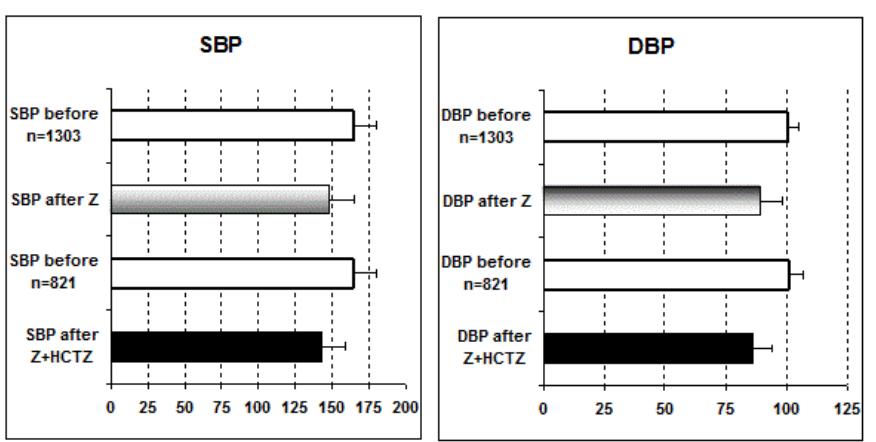

Figure 1. Statistical comparison of systolic and diastolic blood pressure.

Table 2. Response rates and Mantel-Heanszel odd ratios.

\begin{tabular}{|c|c|c|c|}
\hline \multicolumn{3}{|c|}{ Respondersstudies 13-15 } \\
\hline Treatment & \multicolumn{2}{|c|}{$\mathbf{Z}$} & Z+HCTZ \\
\hline $\mathrm{n}$ & \multicolumn{2}{|c|}{886} & 505 \\
\hline$\%$ & \multicolumn{2}{|c|}{76.3} & 82.8 \\
\hline Odd Ratio & lower limit & upper limit & \\
\hline & $95 \%$ & $95 \%$ & p value \\
\hline 1.493 & 1.163 & 1.917 & 0.002 \\
\hline
\end{tabular}




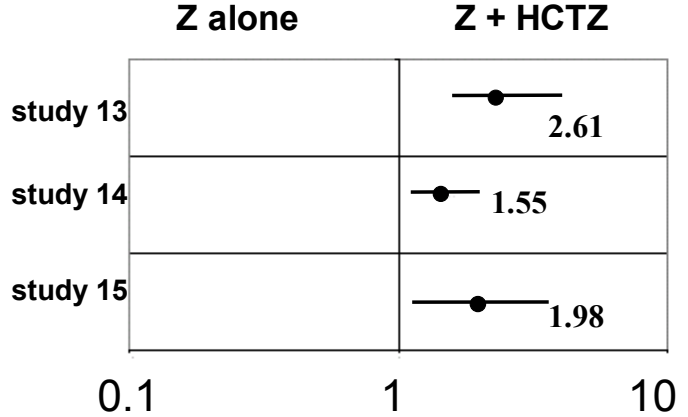

Figure 2. Mantel-Haenszel odd ratios response rates for BP and $95 \%$ confidence interval.

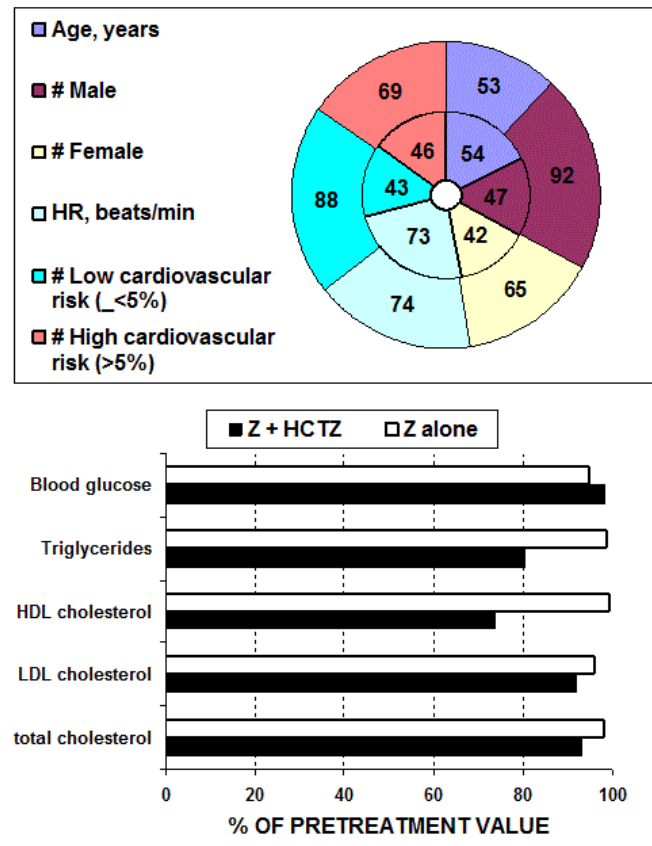

Figure 3. Initial demographic features together with evaluated low or high cardiovascular risk characteristics of the two groups of patients successively treated with:either Z +HCTZ: external ring or with $\mathrm{Z}$ alone: internal ring.

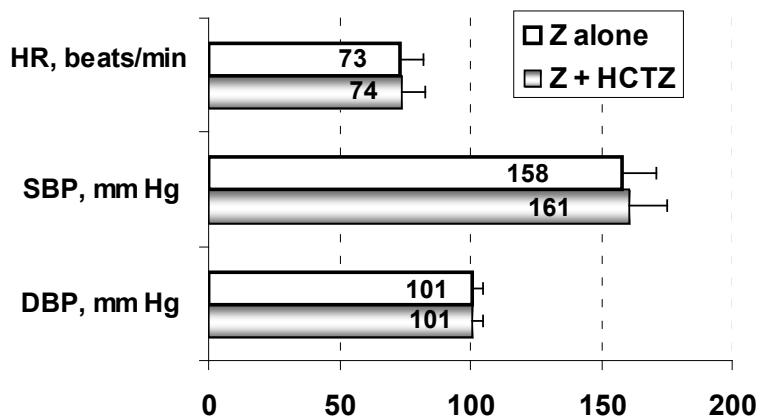

Figure 4. Initial clinical traits (mean \pm S.D.) of the two groups of patients that will be successively treated with either $\mathrm{Z}+\mathrm{HCTZ}$ or with $\mathrm{Z}$ alone.

of the cardiovascular risk appeared significantly $(\mathrm{p}<0.01)$ greater in the combined therapy group than in the monotherapy group: i.e. $1.9 \%$ versus $0.2 \%$, respectively. Furthermore this resulted particularly in the group of patients with the initially highest cardiovascular risk (5.2\% versus $2.0 \%$, respectively). Actually, this study did classified patients in quartiles of cardiovascular risk level (risk of developing a cardiovascular disease in the next 10 years; quartile $1=$ lowest risk, to quartile 4 = highest risk) accordingly to the SCORE Project depicted by Conroy et al., [45].

It appeared that the combined therapy $\mathrm{Z}+\mathrm{HCTZ}$ was followed by significant $(p<0.01)$ reduction in 10 -year risk of cardiovascular disease in patients of the higher-risk quartile. More precisely, 22 out of the 44 patients at high cardiovascular risk had their risk reduced to a lower level after 12 weeks of treatment.

Decreased levels (mean \pm S.D.) of sitting systolic BP (SBP) or office diastolic blood pressure (DBP) as following 12 weeks of treatment, by quartiles $(\mathrm{Q})$ of cardiovascular risk level (quartile $1=$ lowest risk to quartile $4=$ highest risk), in patients (approximately $\mathrm{n}=60$ each $\mathrm{Q}$ ) treated with $Z+\operatorname{HCTZ}(n=157)$ or $Z$ alone.

Statistical significance of the trend of the difference between combined versus mono-therapy over the 4 quartiles was determined by analysis of variance and resulted in a trend $\mathrm{p}<0.01$ (Table 3 ).

Metabolic parameters: Only study [15] present data on metabolic parameters on subjects either treated with $\mathrm{Z}$ or with the combination $\mathrm{Z}$ + HCTZ. No statistically significant difference versus control data could be found after treatment with $\mathrm{Z}$ alone as well as between $\mathrm{Z}$ alone versus the combination $Z+H C T Z$ with respect to the metabolic parameters glucose, total cholesterol, triglycerides, low density lipids (LDL) and highdensity lipids (HDL) -cholesterol. For treatment with $\mathrm{Z}$ alone this was also confirmed in the work from Lacourcière \& Provencher, 1989 [11]. However, and as shown in figure 3, it appears that $Z$ alone and even more $Z+$ HCTZ combined therapy is showing the tendency to reduce metabolic parameters and in particular triglycerides and (HDL) -cholesterol.

\section{Discussion}

Hypertension on its own is the most significant independent risk factor for the development of cardiovascular disease (CVD) that is the most common cause of death in the Western world and is increasing as a significant reason of morbidity and mortality in economically developing nations [17]. For instance, it has been reported that even at high-normal BP levels i.e., SBP 139-130 mm Hg and/or DBP 89$85 \mathrm{~mm} \mathrm{Hg}$ [being the optimal SBP $<120 \mathrm{~mm} \mathrm{Hg}$ and DBP $<80 \mathrm{~mm}$ $\mathrm{Hg}]$ there is an increased risk of CVD (adjusted hazard ratios of 2.5 for women and 1.6 for men [18]. That meta-analysis performed in more than 47.000 patients has also ascertained a risk reduction of $>$ $50 \%$ for heart failure, up to $40 \%$ for stroke and $20-25 \%$ for coronary heart disease when a decrease of $5-6 \mathrm{~mm} \mathrm{Hg}$ in DBP was achieved [18]. Accordingly, the HOT (Hypertension Optimal Treatment) trial that has assessed approximately 19000 patients has shown that the lowest amount of major cardiovascular events goes on at a mean DBP of 82.6 $\mathrm{mm} \mathrm{Hg}$ [19].

An effective treatment of hypertension should result in a reduction in adverse cardiovascular events [19,20]. The ESH/ESC guidelines recommend long-acting treatments administered on a once-daily basis and providing 24-hour efficacy [21], the two major objectives being

Table 3. Decreased levels (mean \pm S.D.) of sitting systolic BP (SBP) or office diastolic blood pressure (DBP).

\begin{tabular}{|c|c|c|c|c|}
\hline SBP decrease & Q1 & Q2 & Q3 & Q4 \\
\hline$Z+$ HCTZ & $-18 \pm 12$ & $-22 \pm 17$ & $-21 \pm 13$ & $-24 \pm 13$ \\
\hline Z alone & $-8 \pm 16$ & $-14 \pm 15$ & $-13 \pm 17$ & $-13 \pm 17$ \\
\hline DBP decrease & Q1 & $\mathbf{Q 2}$ & $\mathbf{Q 3}$ & $\mathbf{Q 4}$ \\
\hline$Z+$ HCTZ & $-14 \pm 6$ & $-14 \pm 9$ & $-14 \pm 9$ & $-15 \pm 8$ \\
\hline$Z$ alone & $-9 \pm 8$ & $-13 \pm 11$ & $-11 \pm 9$ & $-11 \pm 7$ \\
\hline
\end{tabular}


(i) an improved patient compliance while minimising BP variability; (ii) a greater protection against major cardiovascular events and development of target end-organ damage.

In order to treat hypertension with associated risk factors, international guidelines [22,23] propose the use of angiotensinconverting enzyme (ACE) inhibitors, possibly in combination with other antihypertensive drugs, because of their protective effects at cardio, renal and vascular level.

$\mathrm{Z}$ is a sulfhydryl ACE inhibitor highly lipophilic and with tissueprotective properties [4,24-26]. Since its selective, long-acting ACE inhibitory activity, it appears beneficial and well tolerated for the treatment of a number of cardiovascular diseases (eg., acute myocardial infarction, [27-29] heart failure, [30,31] and essential hypertension [32-34].

In high-risk hypertensive patients, adequate blood pressure (BP) control is difficult to achieve with a single antihypertensive drug $[22,23,35]$. This is the reason way various studies have tested the combination of ACE inhibitors with other antihypertensive drugs. In particular, it has been shown that the combination of low-dose HCTZ $(12.5 \mathrm{mg}$ ) with Z $30 \mathrm{mg}$ results in an additional 4 to $8 \mathrm{mmHg}$ antihypertensive effect with favourable tolerability $[13,36]$ and that this combination therapy might be particularly useful in high-risk patients, such as those with metabolic syndrome [37].

\section{Clinical efficacy}

$\mathrm{Z}$ is characterised by long-lasting tissue penetration and sustained cardiac ACE inhibition [38] and three key clinical studies demonstrated that the combination of Z+HCTZ 30/12.5 mg/day was more effective in maintaining BP reductions than either agent administered as mono-therapy [13,39]. Accordingly, such fixed-dose combination is approved in Italy, France, Switzerland and Greece for the management of mild to moderate hypertension. In particular, the first of the three studies were a 12-week, multi-centre, dose-response analysis in 353 patients aged 18-75 years with essential hypertension, where the combined therapy Z + HCTZ (30/12.5 or 60/12.5 mg/day) appeared to be more effective in maintaining continuous 24-hour BP control (i.e. seated DBP $<90 \mathrm{~mm} \mathrm{Hg}$ ), than both compounds used as mono-therapy [13]. The second of the three studies is a 36-week comparison of $Z+H C T Z$ versus zofenopril mono-therapy. It resulted in a significantly $[p<0.01]$ greater efficacy of $Z+$ HCTZ combination therapy in decreasing $B P$ in 463 patients aged $18-75$ years with mild to moderate hypertension. Briefly, they presented after treatment a SBP $<140 \mathrm{mmHg}$ following a SBP reduction $\geq 20 \mathrm{~mm} \mathrm{Hg}$ and a DBP $<90$ $\mathrm{mmHg}$ because of a DBP reduction $\geq 10 \mathrm{mmHg}$ (Table 3 ). The third of the three studies involved 369 patients, 18-70 years of age with mild to moderate hypertension. In fact, the patients of the third study were the "non-responders" to the mono-therapy in study 2 as they were showing $\mathrm{SBP}>=130$ and $\mathrm{DBP}>=85 \mathrm{mmHg}$ and/or SBP reduction $<$ $20 \mathrm{mmHg}$ and/or DBP reduction $<10 \mathrm{mmHg}$ after 4 weeks of singleblind treatment with $\mathrm{Z}$ alone $30 \mathrm{mg} /$ day. Therefore, these 369 patients were successively randomised to double-blind treatment for a further 8 weeks with either $Z$ alone $30 \mathrm{mg} /$ day or with the combined therapy $Z$ + HCTZ 30/12.5 mg/day. It appeared that the mono-therapy again did not reduce significantly SBP and/or DBP. In contrast, the combination $\mathrm{Z}+$ HCTZ was able to significantly reduce SBP and DBP as shown in table 3. Briefly, it appeared that BP reached a plateau at week 8 in patients receiving the mono-therapy while it was progressively decreasing in patients receiving the combined therapy.
463 patients with mild to moderate hypertension $[36,39]$ submitted to mono or combined therapy [parallel group comparative study] for 4 weeks and 369 non responders successively submitted to mono or combined therapy [Non responder study: 8 weeks] (Table 4 ).

\section{Safety and tolerability}

The clinical trials studying the combination $Z+H C T Z$ versus $Z$ or HCTZ mono-therapy and involving about 600 patients reported that dizziness, headache cough [and polyuria] are the predominant adverse events in the combined as well as in the mono-therapy. They are mild to moderate in severity and not linked with age or sex $[13,39,40]$. Thus it is concluded that the combined $\mathrm{Z}+\mathrm{HCTZ}$ therapy results in adverse events as expected with ACE-inhibitor therapy.

In the dose-response study, a total of $9.9 \%$ of patients reported an adverse event, with a majority (64.3\%) of mild intensity [13]. Again in such study the tolerability of $30 / 12.5 \mathrm{mg} /$ day was better than that of $60 / 12.5 \mathrm{mg} /$ day and treatment withdrawal occurred in only $1.7 \%$ of patients. There were no changes in low-density lipoprotein cholesterol, triglycerides, blood glucose or uric acid levels with combination therapy in the dose-response study, a total of $9.9 \%$ of patients reported an adverse event, with a majority (64.3\%) of mild intensity [13]. Again in such study the tolerability of $30 / 12.5 \mathrm{mg} /$ day was better than that of $60 / 12.5 \mathrm{mg} /$ day and treatment withdrawal occurred in only $1.7 \%$ of patients. There were no changes in low-density lipoprotein cholesterol, triglycerides, blood glucose or uric acid levels with combination therapy that also showed no negative effect on heart rate [39]. In addition, in the parallel-group comparative study, the proportions of patients discontinuing treatment because of adverse events were $11 \%$ in the $\mathrm{Z}$ mono-therapy while they were $6 \%$ only in the $\mathrm{Z}+\mathrm{HCTZ}$ combined therapy. Furthermore, no single adverse event resulted in discontinuation for more than $1 \%$ of patients in the combined therapy. Slightly different values comes from reference [16] where the safety profile of zofenopril $30 \mathrm{mg}$ plus hydrochlorothiazide $12.5 \mathrm{mg}$ did not differ significantly from that obtained with the corresponding mono-therapies $(24 \%$ of patients with drug-related adverse events versus $20 \%$ with $\mathrm{Z}$ alone and $17 \%$ with HCTZ alone). Nevertheless, in such study it has been confirmed that the drug combination $Z+$ HCTZ was significantly healthier for patients with the highest level of cardiovascular risk.

\section{ACE inhibitors and end-organ protection}

It has been shown that ACE inhibitors inhibit the formation of angiotensin II [operative molecule of the renin-angiotensinaldosterone system (RAAS)] that has negative effect on endothelial, vascular and renal tissues [41]. Thus, activation of RAAS is implicated in CVD-related morbidity and mortality on top of hypertension, hyperlipidaemia, diabetes $[27,28,42]$. Therefore the negative influence of ACE inhibitors upon RAAS may have a beneficial effect in terms of end-organ protection, in addition to their effects on BP. Indeed, the SMILE (Survival of Myocardial Infarction Long-Term Evaluation) study has established the efficacy of $\mathrm{Z}$ in reducing the mortality due to Myocardial Infarction [43]. In addition, the combination therapy $Z$

Table 4. Patients submitted to mono or combined therapy [parallel-group comparative study]. SBP: systolic blood pressure, DBP: diastolic blood pressure; ${ }^{*} \mathrm{p}<0.05 ;{ }^{*} \mathrm{p}<0.01$.

\begin{tabular}{|l|l|l|l|}
\hline Studies & Treatments & SBP decrease & DBP decrease \\
\hline 463 patients & Z alone & $-12 \mathrm{mmHg}$ & $-10 \mathrm{mmHg}$ \\
\hline & $Z+$ HCTZ & $-20 \mathrm{mmHg} * *$ & $-14 \mathrm{mmHg} * *$ \\
\hline 369 non responders & Z alone & $-8 \mathrm{mmHg}$ & $-6 \mathrm{mmHg}$ \\
\hline & $Z+$ HCTZ & $-10 \mathrm{mmHg} * *$ & $-7 \mathrm{mmHg}^{*}$ \\
\hline
\end{tabular}


+ HCTZ has been proved able to normalise renal morphological and functional alterations, therefore reducing mortality, in hypertensive rats evaluated in an 8-week, placebo-controlled study [44]. Furthermore, and with respect to the metabolic parameters, no significant difference was observed between pre-treatment and treatment data and between $\mathrm{Z}$ as single treatment and the combination $\mathrm{Z}+\mathrm{HCTZ}$ with respect to total cholesterol, HDL and LDL-cholesterol, triglycerides and glucose plasma concentrations $[2,15]$. However, the observed tendency of the combined therapy $Z+\mathrm{HCTZ}$ to reduce these parameters and in particular triglycerides and HDL -cholesterol may support further the positive influence of such treatment within hypertension conditions.

\section{Conclusions}

In general, data from clinical trials evaluated in this and previous meta-analysis indicate that the combination therapy with $\mathrm{Z}+\mathrm{HCTZ}$ $30 / 12.5 \mathrm{mg} /$ day offers superior BP control in a larger amount of patients when compared to mono-therapy with $\mathrm{Z}$ alone $30 \mathrm{mg} / \mathrm{day}$. In particular, studies in references [12-16] are the main source of blood pressure parameters with study in reference [13] being a randomised, homogeneous study showing response rate significantly increased (odd ratio 2.61 [1.55-4.39]) when HCTZ was added to treatment with Z alone. Accordingly, similar [slightly less pronounced] data come from studies in references [14] and [15]. Again, in the study from Malacco, et al. [16] combination treatment with Z plus HCTZ was associated with a significantly greater decrease in BP compared with $\mathrm{Z}$ mono-therapy with the difference between combined therapy and mono-therapy mostly marked for the group of patients at highest risk. Furthermore, data show that the combined therapy preserves the tolerability profile monitored in either Z or HCTZ mono-therapy thus favouring patient compliance.

In general, then it appears that the combined therapy Z + HCTZ has a safety profile although only the study in $[15,45]$ is analysing lipid parameters with yet the evidence that no significant difference in total cholesterol, HDL and LDL-cholesterol, triglycerides and glucose plasma concentrations was detected following treatment with $\mathrm{Z}$ alone or Z + HCTZ versus pre-treatment values.

In conclusion then, the combined therapy $\mathrm{Z}+\mathrm{HCTZ}$ appears to be effective for patients with BP insufficiently controlled by monotherapy. This conclusion is supported by the recent ZODIAC study showing the increased efficacy of 18 weeks of combined therapy $Z+$ HCTZ on previous mono-therapy treated patients [46].

Long-term larger randomized clinical trials are yet needed to establish that the Z + HCTZ combination has the same cardiovascular and renal protective effects demonstrated by other ACE inhibitors.

\section{References}

1. Düsing R (2001) Adverse events, compliance, and changes in therapy. Curr Hypertens Rep 3: 488-492.[Crossref]

2. Mancia G, Seravalle G, Grassi G (2003) Tolerability and treatment compliance with angiotensin II receptor antagonists. Am J Hypertens 16: 1066-1073.[Crossref]

3. Burnier M1, Santschi V, Favrat B, Brunner HR (2003) Monitoring compliance in resistant hypertension: an important step in patient management. J Hypertens Suppl 21: S37-42.[Crossref]

4. Napoli C, Sica V, de Nigris F (2004) Sulfhydryl angiotensin converting enzyme inhibition induces sustained reduction of systemic oxidative stress and improves the nitric oxide pathway in patients with essential hypertension. Am Heart J 148:e5.

5. Mancia G, Zanchetti A, Agabiti-Rosei E, Benemio G, De Cesaris R, et al. (1997) Ambulatory blood pressure is superior to clinic blood pressure in predicting treatmentinduced regression of left ventricular hypertrophy. SAMPLE Study Group. Study on Ambulatory Monitoring of Blood Pressure and Lisinopril Evaluation. Circulation 95:

\section{4-1470.[Crossref]}

6. Zanchetti A (1999) Contribution of fixed low-dose combinations to initial therapy in hypertension. Eur Heart J Supplements1: L5-L9.

7. Lewis EJ, Hunsicker LG, Bain RP, et al. (1993) The effect of angiotensinconvertingenzyme therapy on diabetic nephropathy. N Eng J Med 329: 1456-62.

8. Giatras I, Lau J, Levey AS (1997) Effect of angiotensin-converting enzymeinhibitors on the progression of nondiabetic renal disease: A meta-analysis of randomized trials. Ann Intern Med 127: 337-45.

9. Zanchetti A, Ruilope $\operatorname{LM}(2002)$ Antihypertensive treatment in patients with type-2 diabetes mellitus: what guidance from well controlled randomized trials? J Hypertens 20: $2095-110$.

10. Lacourcière Y, Gagné C (1989) Influence of zofenopril and low doses of hydrochlorothiazide on plasma lipoproteins in patients with mild to moderate essential hypertension. Am J Hypertens 2: 861-864.

11. Lacourcière Y, Provencher P (1989) Comparative effects of zofenopril and hydrochlorothiazide on office and ambulatory blood pressures in mild to moderate essential hypertension. Br J Clin Pharmacol 27:371-376.

12. Malacco E, Omboni S (2007) Antihypertensive efficacy of zofenopril plus hydrochlorothiazide fixed combination for treatment in metabolic syndrome. Adv Ther 24: 1006-1015.[Crossref]

13. Parati G, Omboni S, Malacco E (2006)Antihypertensive efficacy of zofenopril and hydrochlorothiazide combination on ambulatory blood pressure. Blood Pressure 1: 7-17.

14. Mäkel WNA(2007) Multi-center, open PMS to evaluate the efficacy, tolerability and safety of zofenopril during treatment of hypertension protocol number ZOF/PMS/NL01/02.(Unpublished).

15. A multi-center, open PMS to evaluate the efficacy, tolerability and safety of zofenoprilduring treatment of hypertension in diabetic patients in Internal Medicine practice protocol number MeBN/03/zof-PMS/01 (Unpublished).

16. Malacco E, Omboni S (2008) Antihypertensive Effect of Zofenopril Plus Hydrochlorothiazide Versus Zofenopril Monotherapy in Patients with Essentia Hypertension According to Their Cardiovascular Risk Level: A Post Hoc Analysis. Current Therapeutic Research 69: 232-224.

17. Ezzati M, Lopez AD, Rodgers A, Vander Hoorn S, Murray CJ (2002) Selected major risk factors and global and regional burden of disease. Lancet 360: 1347-1360. [Crossref]

18. Vasan RS, Larson MG, Leip EP, Evans JC, O’Donnell CJ, et al. (2001) Impact of highnormal blood pressure on the risk of cardiovascular disease. N Engl J Med 345: 12911297.[Crossref]

19. Hansson L, Zanchetti A, Carruthers SG (1998)Effects of intensive blood-pressure lowering and low-dose aspirin in patients with hypertension: principal results of the Hypertension Optimal Treatment (HOT) randomized trial. Lancet351: 1755-62.

20. Collins R, MacMahon S (1994) Blood pressure, antihypertensive drug treatment and the risks of stroke and of coronary heart disease. Br Med Bull 50: 272-98.

21. European Society of Hypertension-European Society of Cardiology Guidelines Committee (2003) 2003 European Society of Hypertension-European Society of Cardiology guidelines for the management of arterial hypertension. J Hypertens 21 : 1011-1053.[Crossref]

22. Mancia G, De Backer G, Dominiczak A, Cifkova R, Fagard R, et al. (2007) 2007 Guidelines for the management of arterial hypertension: The Task Force for the Management of Arterial Hypertension of the European Society of Hypertension (ESH) and of the European Society of Cardiology (ESC) J Hypertens 25:1105-1187.[Crossref]

23. Chobanian AV, Bakris GL, Black HR, Cushman WC, Green LA (2003)The seventh report of the Joint National Committee on Prevention, Detection, Evaluation, and Treatment of High Blood Pressure: JNC 7 report JAMA 289: 2560-2572.[Crossref]

24. Pasini AF, Garbin U, Nava MC, Stranieri C, Pellegrini M (2007)Effect of sulfhydry and non-sulfhydryl angiotensin converting enzyme inhibitors on endothelial function in essential hypertensive patients. Am J Hypertens 20: 443-450.

25. Evangelista S, Manzini S (2005) Antioxidant and cardioprotective properties of the sulphydryl angiotensin-converting enzyme inhibitor zofenopril.J Int MedRes 33: $42-54$.

26. Altunoluk B, Soylemez H, Oguz F (2006) An angiotensin-converting enzyme inhibitor, zofenopril, prevents renal ischemia/reperfusion injury in rats. Ann Clin Lab Sci 36: 326-332. 
27. Borghi C, Ambrosioni E (2003) Double-blind comparison between zofenopril and lisinopril in patients with acute myocardial infarction: Results of the Survival of Myocardial Infarction Long-term Evaluation-2 (SMILE-2) study. Am HeartJ 145: 8087.

28. Borghi C, Bacchelli S, Esposti DD, et al, (1999) Effects of the administration of an angiotensin-converting enzyme inhibitor during the acute phase of myocardial infarction in patients with arterial hypertension. AmJ Hypertens 12: 665-672.

29. Borghi C, Bacchelli S, Esposti DD, Ambrosioni E (2003)Effects of the early ACE inhibition in diabetic nonthrombolyzed patients with anterior acute myocardial infarction. Diabetes Care 26: 1862-1868.

30. Kelbaek H, Agner E, Wroblewski H (1993) Angiotensin converting enzyme inhibition at rest and during exercise in congestive heart failure. Eur HeartJ 14: 692-695.

31. Binkley PF, Haas GJ, Starling RC, et al. (1993) Sustained augmentation of parasympathetic tone with angiotensin-converting enzyme inhibition in patients with congestive heart failure. J Am Coll Cardiol 21:655-661.

32. Elijovich F, Laffer CL, Schiffrin EL (1997) The effects of atenolol and zofenopril on plasma atrial natriuretic peptide are due to their interactions with target organ damage of essential hypertensive patients.J Hum Hypertens 11: 313-319.

33. Leonetti G, Rappelli A, Omboni S (2006)A similar 24-h blood pressure control is obtained by zofenopril and candesartan in primary hypertensive patients. Blood Press 15: $18-26$.

34. Malacco E, Piazza S, Omboni S (2005) Zofenopril versus lisinopril in the treatment of essential hypertension in elderly patients: A randomised, double-blind, multicentre study. Clin Drug Investig 25:175-182.

35. Moser M, Setaro JF (2006) Clinical practice. Resistant or difficult-to-control hypertension. N Engl JMed 355: 385-392.

36. Zanchetti A, Parati G, Malacco E (2006) Zofenopril plus hydrochlorothiazide: Combination therapy for the treatment of mild to moderate hypertension. Drugs 66 : 1107-1115.
37. Malacco E, Omboni S (2007) Antihypertensive efficacy of zofenopril plus hydrochlorothiazide fixed combination for treatment in metabolic syndrome. Adv Ther 24: 1006-1015.

38. Borghi C, Ambrosioni E (2000) Zofenopril: a review of the evidence of its benefits in hypertension and acute myocardial infarction. Clin Drug Invest 20: 371-84.

39. Malacco E, Omboni S (2005) Antihypertensive efficacy of zofenopril plus hydrochlorothiazide fixed combination is superior to that of single components. Eur Heart J 26: 401

40. Zozide prescribing information (2005) Menarini International Operations Luxembourg S.A.

41. Toto RD, Rinner S, Ram CVS (2004) ACE inhibitors and target organ protection: an expanded role for these antihypertensive agents? Postgrad Med 116: 11-6.

42. Dzau V (2005) The cardiovascular continuum and renin-angiotensin-aldosterone system blockade. J Hypertens 1: S9-S17.

43. Ambrosioni E, Borghi C, Magnani B (1995)The effect of the angiotensin-convertingenzyme inhibitor zofenopril on mortality and morbidity after anterior myocardia infarction. N Engl J Med 333:80-85.

44. García-Estan J, Ortiz C, O’Valle F (2006)Effects of angiotensin converting enzyme inhibitors in combination with diuretics on blood pressure and renal injury in nitric oxide deficiency induced hypertension in rats. Clin Sci110: 227-233.

45. Conroy RM, et al. (2003) Estimation of ten-year risk of fatal cardiovascular disease in Europe: the SCORE project. Eur Heart J 24: 987-1003.[Crossref]

46. Agabiti-Rosei E, Manolis A, Zava D, Omboni S (2014) ZODIAC Study Group, Zofenopril plus hydrochlorothiazide and irbersartan plus hydrochlorothiazide in previously treated and uncontrolled diabetic and non-diabeticessential hypertensive patients. Adv Ther 31: 217-233.

Copyright: (C2017 Crespi F. This is an open-access article distributed under the terms of the Creative Commons Attribution License, which permits unrestricted use, distribution, and reproduction in any medium, provided the original author and source are credited. 